1. We degnes to which the habits and circumotances of a pritint $\operatorname{con}$ be controlled and regulated, and the proWib refency of the remedies applied, with the view in ropect of them all $(a)$ of returding the progress of the wint affection, - (b) of warding off secondary affections, and $(c)$ of remoring these when they supervene: these creral objects furmishing at the same time the main indiculions of TBEATXEST.

Southampton, July 28,1854

\section{CLINICAL REMARKS ON CYSTIC SARCOMA AND CANCER OF THE FEMALE BREAST.}

\section{By JOSEPH SAMPSON GAMGEE.}

Swow as must always be the march of knowledge, it is somewhat depressing to reflect that in the science of medicine, which more closely than any other affects the welfare of men, there are special reasons which obstruct progress in addition to those operating in other departments of knowledge. Such is the complexity of the animal organisation, so numerous and difficult are the laws which govern it in health and in disease, that even when to its study can be brought the aid of physical instruments, the task is one of uncommon labour, beset with extraordinary fallacies, as even the most sceptic may satisfy himself, who reflects upon the history of the innovation and introduction into practice of the stethoscope and microscope. The former has achieved its victories, the battle of the latter is being fought. Though there is ample proof that but for the microscope a large number of pathological facts of clinical value, now known, would never have been discovered; though there is good reason to hope that we have barely tasted its fruits; many surgeons in high stations treat it lightly, while others openly deny its practical ntility. Cancer is the field on which its value to surgeons will in great measure have to be decided; and this will be immense, if, after ascertaining by microscopic investigation the anatomical characters of morbid grow ths and classifying these accordingly, it can be determined that the anatomical characters of cancer are as peculiar as their clinical history ; that a tumour not presenting the anatomical character of cancer does not entail upon its possessor any of the evils of this disease; and consequently that in prognoais, at least, immense aid will be afforded by the results of microscopic observation.

It seemed as if this great boon had resulted from the application of the microscope; but there are facts on record in the writings of Mr. Erichsen, Mr. Birkett, and Mr. Paget, which throw a great doubt upon the reality of the discovery, if they do not altogether prove that a benignant tumour, though completely removed by the knife, may be succeeded by an affection in anatomical characters and effects inseparable from secondary cancer. I do not assent to the validity of the proof, because impressed with the belief, that not only has not sufficient care been taken for excluding fallacy from the observation of the facts upon which it is founded, but that their impartial and rigorous study leads to conclusions opposed to those which the above named distinguished authorities have inferred from them.

I shall first relate the case which has given rise to the discussion.

Case. Catherine Edwardes, * aged 42, was admitted into University College Hospital, 9th June, 1851. She was married, and the mother of two children. She had always enjoyed good health and regular catamenia.

Bistory of the present Affection. Three years ago, she felt a small lump about the size of a nut, very hard and readily moreable, beneath the integument situate in the right mamma just above the nipple, not at all painful. She could nat account for it in any way. From the time she first

- It is but just to state that no such correct account as the above has been - It is but just to state that no such correct account as the sbove has been Felished of the history of this case. The report in the Lancet of 31st Jan.

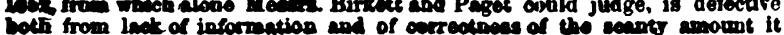
cappliea. noticed the tumour it gradually increased in size, till it bo came as large as an egg. It remained for some time of this size, and it was perfectly movesble benenth the skin, and painless, till three months ago, when it rapidly enlarged and became the seat of a sharp, shooting pain, which she compares to the sensation of a dog gnawing a bone; this pain was most severe at night. She had grown much thinner during the last three months, but no weaker, her appotite remaining good.

State on Admission. She was robust and healthy looking. The tumour in the right mamma was nearly hemispherical, about four inches in the maximum diameter. The skin, of natural colour, did not appear connected with it in the slightest degree, with the exception of slight retraction of the nipple. The tumour was very firm and solid, but one or two points could be detected on carcful examination, somewhat softer than the rest of the surface. When touched, it was only painful at a point on the right side. It was, however, very painful at night. She said it got larger and more painful every day. A group of indurated lymphatic glands was felt in the right axilla.

On the 18th June, the mamma as well as the axillary glands were removed by the knife. The progress of the case was exceedingly favourable; and on the 3rd July the patient was discharged in very good health with the wound neariy healed; but before the end of August, while I was acting as house-surgeon, she returned to the hospital with an affection of the cicatrix, presenting all the characters of secondary cancer. Before operation, there was some doubt as to the nature of the tumour; the softish points detected on palpating its surface were regarded as cysts, and notwithstanding the patient's age, the serere gnawing nocturnal pain, retraction of the nipple and enlargement of the lymphatic glands, the cystic formations were regarded as indications of the benignancy of the tumour, and it was diagnosed for cystic sarcoma. No cancer-cells appearing upon its being submitted to careful microscopic examination, the diagnosis of benignancy was held to be indisputably confirmed, and accordingly a favourable prognosis was pronounced. No notes were taken of the microscopic examination, but I perfectly remember observing at the time that all the specimens which I placed in the field contained a large number of compound granular corpuscles; that they were the most beautiful ones I had ever seen; and it was only then that I whs convinced that the delicate objects depicted under that name in Lebert's Atlas de Physiologie Pathologique, really exist in nature. It is not irrelevant to state that $I$ was in no degree prepared to discover histological evidence of benignancy myself; for before the operation I had tenaciously held to the opinion I had formed on first seeing the case, as to its being a bonci fide cancer.

This case having been reported in the Lasscet of 31st January, 1852, under the head of " Recurrence of a Cystic Sarcoma of the Breast," Mr. Birkett in the subsequent number of that journal called attention to the subject, for the reason of its being so "important in a practical as well as pathological point of view". After adducing reasons why the case must be regarded as one of carcinoma succeeding cystic sarcoma, rather than as a recurrence of the latter disease, Mr. Birkett remarks, "tilc derelopment of carcinoma subsequent to cysto-sarcoma is happily very rare, and this case is a valuable contribution to our imperfect knowledge of the natural history of this form of mammary disease. A case of this kind is reported hy Dr. Bruck (die Diagnose der bösartigen Geschwülste, case ix, s. 9i), which was observed in the clinique of Professor Chelius. The heads of the case are as follows. A cyst containing fluid and intracystic growths was removed from the right mamma. The patient continued to enjoy good health for twelve years. A tumour was then developed in the same breast, which with some axillary glands werc removed. This tumour is described by the name of carcinoma reticulare. The disease returned, infiltrated the skin around the cicatrix and the muscles of the mammary region, and the roman at last died. The necropsy revealed the existence of several carcinomatous growths in various regions of the 
body." In the following number of the Lancet (14th February), Mr. Erichsen concurred with Mr. Birkett that this case must be regarded as one of the very rare eramples of scirrhus appearing in the cicatrix after the removal of the breast for cysto-sarcoma. Mr. Erichsen adds, "a second case of the kind has, however, very recently cocurred to me in private practice, which is not only interesting as affording another instance of this peculiar sequence of pathological conditions, but also as bearing upon point adverted to by Mr. Paget in his recent lectures on tumours: that this appearance of a malignant growth upon the removal of a non-malignant tumour is especially apt to occur in those in whom there is an hereditary tendency to cancer. Last March, I removed a tumour the size of an orange from the breast of an unmarried lady about forty years of age, which had existed for four years, during which period it had at one time almost entirely disappeared under treatment, returning again about two years after its removal. This tumour was perfectly moveable, loosely attached by a broad pedicle to the mammary gland and had in no way implicated any of the neighbouring structures. After removal it presented the appearance of a chronic mammary tumour, with small cysts scattered through its substance; in fact, one form of cystic sarcoma, in illustration of which I used it in my lectures. Neither to the naked eye nor to the microscope did it offer any appearance of malignancy. About three months after its removal, hard nodulated masses appeared in the cicatrix. These rapidly increased in size, and were speedily followed by considerable enlargement of the axillary glands, which had not previously existed. There was now no doubt in my own mind, nor in that of three or four other surgeons who saw this patient in consultation with me, that the secondary disease was well-marked scirrhus. Death occurred five months after the re-appearance of the disease from erysipelas and general exhaustion. I have since learned that three of this lady's aunts had been the subjects of cancer." Again, in his work on The Science and Art of Surgery (p. 717), Mr. Erichsen alludes to these two cases as evidence that a recurrence of cancer will occasionally take place in the cicatrix after the removal of cystic sarcomatous growths.

Mr. Paget has thus commented upon this subject in his lectures on Surgical Pathology (vol. ii, p. 259). "It has sometimes happened that a glandular tumour has been removed from a breast, and within a short time the same breast has become the seat of cancer. (See such a case by Mr. Erichsen in the Lancet, 14th January, 1852; and the history of a scries of preparations in the catalogue of the museum of St. Bartholomew's, vol. i, p. 446)."

From these facts, then, it appears that a disease possessing the anatomical and clinical characters of secondary cancer may occur without any antecedent malignant affection, merely as a sequel of the benignant growth known as cystic sarcoma. The evidence upon which this proposition rests I shall examine under four heads. 1. The case of Catherine Edwardes; 2. The case quoted by Mr. Birkett from Bruck; 3. The second case reported by Mr. Erichsen; 4. Mr. Paget's cases.

1. As to the case of Catherine Edwardes. Her narrative was one of the most common among women labouring under cancer of the breast. The general feel of the tumour, the slight retraction of the nipple, the group of indurated lymphatic glands in the axilla were confirmatory of the judgment to which the anamnesis pointed. The doubt of cancerous nature and diagnosis of cystic sarcoma rested exclusively on the feeling one or two soft points-supposed cysts-upon the surface. "When a cyst is formed on a basis of scirrhus," says Dr. Walshe (On Cancer, p. 481), "an uncommon combination in the female breast, great difficulty of diagnosis arises, and is only to be overcome by a careful estimate of the whole progress of the case." The case under consideration was precisely one in which very great importance could not be attached to the cysts; they were few and very small, and the patient's history, no less than the chief facts ascertained upon her examination coincided accurately with what we know of the progress of scirrhus. When, how- ever, compound granular corpuselice, instend of cancereelly, appeared upon microscopic examination, benignancy was mo longer questioned, and the case was a theme of rejoicing, affording evidence of the microscope's extraordinary value; just as some months afterwards it was ironically dwelt upon as proof of the microscope's deceptiveness. But were those who used the microscope infallible? They were myself and two other gentlemen habituated to microscopic investigation. We all agreed upon what we saw ; compound granular corpuscles; we all believed that these only occur (as the predominaut histological elements) in benignant growths, and that the cell characteristic of cancer was not present in this case. Apparently the basis of our opinion was solid, but very little will suffice to demonstrate its singular frailness. We observed and reasoned, assuming tro things, neither of which was at that time proved: 1. That the so-called granular corpuscles-Gluge's compound inflammatory globules-only occur in benignant growths; 2. That cancerous growths always contain a peculiar cell, in the absence of which cancer cannot be said to exist. Our error was common to the great majority of those who have discussed the diagnostic value of the cancer-cell. We ressoned before the fact; having verified the statement that a peculiar cell is usually met with in oancer, we assumed it to be an invariable characteristic histological element, and that consequently, in its absence, cancer could not be said to exist. This was begging the question wholesale. Several thousand tumours, including all varieties, should have been examined and classified according to anatomical characters before a judgment was pronounced as to the diagnostic value to be attached to the presence or absence of certain histological elements. In the then state of knowledge, considering the history of the cases, all that we were warranted in, upon discovering the granular corpuscles, was to suspend judgment as to the cancer diagnosis; when, howerer, after the removal of the primary tumour the cicatrix became the seat of a disease presenting the typical characters of secondary cancer, the only logical, and therefore the only practical conclusion was, that this was a case in which the so-called cancer-cell had not been discoverable in a tumour, though the antecedent and subsequent history of the patient decidedly conformed to the progress of cancer as clinically observed. Repeated and progressively more enlightened microscopic inquiry has inspired me with the belief that the tumour of Catherine Edwardes probably did contain cancer cells, but that from their being stuffed with fat molecules we mistook them for compound granular corpuscles. Of the case which first inspired me with this belief, record is preserved in my microscopic sketch-book. To the drawing of a large cell with delicate outline and large coarsely granular nucleus is appended the following note. "This cell is from a cancerous nodule in the liver of a spinster, aged 70 , whose autopsy was made in University College Hospital by Mr. John Marshall, on the 10th September, 1852. The left mamma was the seat of primary disease, not operated upon. My motive for drawing this cell is that in two large fields (one-fourth of an'inch) it is the only one I have seen so distinctly, all the others being clouded by an immense number of fat granules, many of which are free, which stud the cells and nuclei, so as to give the appearance of finely granular corpuscles. On adding ether, only oilglobules remain visible; cells, nuclei, and molecules having apparently been alike completely destroyed. In those cells in which the cell wall is visible, it is very faint; the nucleus, where not completely hidden from view by surrounding granules, is rery large. Was it such a fat granular condition of cells as this that gave rise to the appearance of compound granular corpuscles in Catherine Edwardes ?"

I think it quite possible that, with the aid of recent experience and more careful investigation, the so-called cancer-cells might now be found even in such a tumour as was removed from Catherine Edwardes. This surmise aside, the facts I have related, and the observations appended to them, are, I conceive, such that the case can no longer be regarded as an example of malignant disease affecting a cicatrix after the removal of a benignant tumour. 
2. The fact of the case which Mr. Birkett has cited from Bruck as a parallel to that of Catherine Edwardes, cill for analytical study. The heads of Dr. Bruck's case are as follows:-“A cyst, containing fluid and intra-cystic growths, was removed from the right mamma. The patient continued to enjoy good health for twelve years. A tumour cas then developed in the same breast, which, with some exillary glands, was removed. This tumour is described by the name of carcinoma reticulare. The disease returned, infiltrated the skin around the cicatrix and the muscles of the mammary region, and the woman at last died. The necropsy revealed the existence of several carcinomatous growths in various regions of the body." From these facts I infer that the woman in question was the subject of a benignant cystic tumour of the right mamma, and was successfully relieved of it by the knife; that, twelve years afterwards, the same breast became the seat of a primary cancerous tumour, the removal of which by the knife did not prevent the recurrence of fatal cancerous disease, between which and the cystic growth of so many years previously, known facts do not justify me in acknowledging any sequential relation. My right may be questioned to call the first cystic tumour benignant; I am induced to think it very probably was such by the history of the case, and by the fact that nothing is said of its being cancerous; whereas the cancerous nature of the subsequent formations is specifically mentioned. It is of course easy to understand that a mamma which has been the seat of a benignant tumour is subsequently at least quite as liable as a healthy gland to become the seat of primary cancer. Though granting that Mr. Birkett had not opportunity for judging fully the fruits of Edwardes's case, I must confess myself unable to see the grounds upon which he established a parallel between it and the case of Dr. Bruck.

3. Mr. Erichsen has published, in support of Edwardes's case, a case quoted in the early part of this communication, which, prima vista, is unimpeachable. At the time when Mr. Erichsen reports having remored the second tumour (March 1851), I attended his lectures, in which he states he used it as an illustration of cystic sarcoma. 1 perfectly remember his submitting to the observation of the class a mammary tumour as a good example of cystic sarcomatous disease, and his kindly giving a portion of it to my friend Mr. Juseph Lister and myself. Our microscopic examinations were conducted independently, and, on meeting at next day's lectures, we both expressed to Mr. Erichsen our doubts as to the benignancy of the tumour, as we had observed appearances which we thought characteristic of cancer. Mr. Lister had additionally made a sketch of them. Possibly the case I allude to and the one reported by Mr. Erichsen are not the same: it would indeed be curious if two such varieties should occur in the same month. I have no doubt that, considering the great importance of the question, Mr. Erichsen will supply all the evidence connected with his case, if it be really, as appears from his brief account of it, an example of secondary scirrhus occurring directly after cystic sarcoma. But even if, in the microscopic examination to which Mr. Erichsen alludes, no signs of malignancy were detected, the case is to some extent liable to the criticism I have made upon Edwardes; on one account more so, because in Mr. Erichsen's patient there was the additional evidence of hereditary predisposition in favour of the diagnosis of cancer, three of the lady's aunts having been the subjects of this disease.

Mr. Paget's opinion regarding Edwardes's case will, I presume, undergo modification when he becomes acquainted with the history I have given of it, he not having had the means of judging correctly in the short account of the Lancet. Not having examined the preparations referred to by Mr. Paget in the Museum of St. Bartholomew's Hospital, I am unable to judge what weight is to be attached to them in the solution of the pending problem.

It is a conviction that the march of knowledge suffers more from the introduction of errors due to imperfect obarvation and precipitate generalisation, than from the clowneas of progreas dependent upon the difficulty of inves- tigation, which has made me thus analytically and critically examine evidence tending to invalidate some of the most important propositions deduced from careful and prolonged study. If those propositions be not sound, the sooner they are proved false the better; but the evidence adduced against them must at least be as valid as that upon which they are based.

It may not be inappropriate to append from my notebook the histories of other two cases, in which, from the existence of cysts on scirrhous bases, the diagnosis was difficult, but in which the microscope cleared up the doubt.

CASE. K. G., aged 59, had never been a strong woman, but always healthy. Catamenia appeared first at 15, last at 47 years. She had had nine children and six miscarriages. She had never heard of cancer or tumours of breast in any of her family. Five years ago, a little tumour, about as large as the end of the little finger, appeared just under the skin above the left nipple. She could move it easily. It was of about present hardness, not painful, nor had it ever been so, with the exception of the last month, when she had occasionally, while wringing clothes, felt a little pain on its inner side for a few minutes. She spontaneously described the pain as the pricking occasioned by a needle, but it has been very trifling. For about a year the tumour did not grow, but it had since gradually enlarged. She thinks it had grown most rapidly in the last twelve months; during the same period, the skin covering it had become discoloured.

The tumour occupied the left breast, was about as large as a good sized apple, irregularly spheroidal, and inseparably counected with the gland. Its base, especially on the outer side, was very hard; but at the anterior and upper part, over a surface one inch square, the tumour was made up of tolerably distinct softish elastic nodules, apparently cysts containing liquid. Among these elastic nodules was a very hard one. This part of the tumour was decidedly more prominent than any other, and was moreover peculiar for the livid discolouration of the superjacent skin, and its being more adherent to it than was the substance of the tumour to the integument in other parts. There was no adhesion to pectoral muscles. The nipple was slightly retracted. Just within the anterior fold of the left axilla was a very hard lymphatic gland, pcrfectly smooth, not at all tender, about as large as a filbert.

The diagnosis would hare been easy but for the cystic complication. The surgeon under whose treatment $\mathbf{K}$. $G$. was placed diagnosed her tumour as a cystic sarcoma, and non-cancerous, for the following rcasons:-1. The tumour was not adherent to the pectoral muscles. 2. There was no dimple in the skin. 3. Scarcely any pain was complained of. 4. Well developed cysts were present. My opinion having been requested, I diagnosed the tumour as scirrhous associated with cysts. The absence of adhesions to the pectoral muscles, and of dimpling of the skin, the almost painlessness of the tumour, were not serious objections: scirrhous tumours are often met with in those conditions. The patient's age, the very marked hardness of the tumour's base, the slight retraction of the nipple, the enlarged and indurated axillary glands, rere signs of cancer. Cysts, though rarely, are occasionally developed on a scirrhous base.

The affected mamma having been excised on the 12th of January, 1853, my diagnosis was proved correct by examination of the tumour, of which the following notes were taken at the time:-The elastic nodules at its upper and anterior part proved to be cysts filled with turbid serosity. There were three or four of them, each capable of containing a cherry-stone. The substance of the tumour was firm on section, but it did not grate under the knife. The cut surface presented numerous little yellow spots, about the size of pins' heads, studding a whitish, uniform, and somewhat cartilaginous looking tissue. At several parts were little masses of yellow soft substance, which, under the microscope, was found to consist of oil-globules in large numbers, and of large cells, some of which were so stuffed with 
Connles as to be quito black; others, laes gramular, showed there nuolous and nucleolus in their interior. On preacing the trmour, milky whice fluid escoped in drope from the curvee. In this fuid, as well as in scrapings from the trmour, ware seen histological alements unmistakeaby cancomous.

I had been greatly aided in the diagnosis of the foregoing cases, by having a short time previously had one in many reapects similar to it under observation in the great Plarence hospital.

Casz. Faustina Franchi, admitted to No. 154 of Professor Regnoli's Clinique on the 18th of Jan., 1852, the mother of fourteen children, always enjoyed excellent health. No trace of hereditary predisposition to cancer.

The left nipple was slightly but decidedly retracted. In the npper part of the corresponding mamma. and insepambly connected with it, was an irregularly square shaped tumour, almost as large as a small orange, non-adherent to the skin or subjacent tissues, finely nudulated and very hard, except at its supero-anterior part, where a cyst, about a large as a walnut, rose from the hard base, so as to form a notable prominence on the surface. There was an indurated lymphatic gland, about three times its normal size, in the left axilla. The mammary tumour had oceasionally been the seat of a dragging sensation, but never of pricking or stabbing pain. Handling it produced no inconrenience.

Interrogated as to the history of the tumour, the patient stated that, after her first and second confinements, abscesses formed in the left mamma, and for the time prerented her suckling with it: she had ever since been able to suckle with both breasts, but the left one had diminished somewhat in size, was generally harder, especially at the npper and inner parts, and yielded somewhat less milk. She stated positively that, when last confined (eleven months before admission into the clinique), the only difference between the two mammæ consisted in the smaller size and greater hardness of the left one, especially at its upper and inner part. She suckled even her last infant with both breasts; they both contained a good deal of milk when I first examined her, and on admission. It was not until seven months after her last confinement, and four months before admission in hospital, that she became aware of the existence of the tumour: its size had since then rapidly increased.

The history of this case was obscure; and though the very hard base of the tumour, retraction of the nipple, and enlarged axillary glands, indicated its scirrhous nature, I was only positive of it after the operation, which was performed by Professor Regnoli on the 13th of February. On section, the cyst at the upper and anterior part proved to be filled with a limpid serous fluid. The cut surface of the tumour typically presented the appearance of scirrhus, and microscopic examination unmistakeably confirmed the judgment based on the naked eye characters of the section.

I cannot close these remarks without an expression of regret that we should still be obliged to make use of the term eystic sarcoma, which is for all useful purposes meaningleas. It, like many others in pathology, is the heritage of ignorance, and will only be aptly replaced when knowlodge is fully attained. A new nomenclature, before the facts are known to render classification possible, would only add confusion, and have in its turn to be swept away. What we want are plenty of correct facts and severe reasonings to ensure progress at the desirable rate in the road now being so auspiciously trodden by a considerable number of scientific labourers. Meanwhile, the least possible use should be made of the most objectionable terms, and their signification be defined by the addition of circumstantial information. If every one who contributed a single fact or idea to the common stock reflected that its utility is often mose than counterbalanced by admixture with an imperfect observation or lax argument, the march of knowwould be more rapid, even though the number of fiecovered continued in the same ratio.

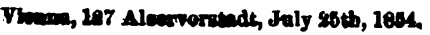

\section{LACTIC ACID IN DYSPEPSIA.}

\section{By C. HANDFTELD JONB8, M.D., Abistent-Physicien to} St. Mary's Hospital.

As far as I am aware, lactic acid has not as yet been em ployed to any extent in medicine. It was originally recommended by Magendie, as Dr. Pereira mentione, but it does not seem to have found much favour, in the ejes of British practitioners at least. The idea suggested itself to me some time ago, before 1 was aware that it had been recommended by others, of employing it as a remedy in dyspepsia. I have tried it in several instances, and have been so well satisfied with its effects, that I cannot but regard it as an useful addition to the materia medica. I have taken it myself, and experienced no unpleasant results, but on the contrary, as it seemed to me, the digestive faculty was invigorated. I have chiefly given it in cases of irritative dyspepsia where the digestion was painful and imperfect, and had been so for some time. I should not advise its being given quite at the commencement of the treatment in a severe case of the kind, but after the irritation and vascular erethism had been somewhat reduced. The romedy should be given in doses of mexv-xx in 3 ss of water, and it should be taken at meal times. It seems to mingle with the food, and supply one of the constituents of healthy gastric juice which is probably imperfectly produced. Its use need not be confined to cases of dyspepsia, but may be extended to all cases where it is desirous to improve the tone and power of the stomach. It is a pleasant medicine, occupies but a small space, and may almost be placed on the table as one of the ordinary condiments. In the management of a tedious case of dyspepsia and debility, where patients and doctors are getting tired of formal bottles of physic, I can sincerely recommend a little vial of lactic acid to be brought on the table with the meal, as an agreeable and efficient substitute. The only objection to its use is that it is rather expensire; but if a demand for it should be created, the price would no doubt be lowered.

The article which I have used has been prepared for me by Mr. Blades, 52 , Edgeware Road.

Lcndon, August 185.1.

\section{CASE OF PUERPERAL CONVULSIONS IN} WHICH TRACHEOTOMY WAS PERFORMED.

\section{By E. WILLIAMS, M.D.}

[Read at the Anmual Mecting of the North Wales Branch at Rhyl, August 0th, 185t.]

I PROPOSE to make a few remarks upon a case of puerperal convulsions which occurred in my practice in the spring of the present year; not that the case itself merited especial notice, or differed essentially from this dreadful malady whenever it presents itself, but that I may direct attention to a means of relief which, as far as I am awars, has not previously been put into practice-that of tracheotomy.

CASE. Mrs. G_ a a a twed twity-nine, the wife of a farmer, a pale delicate little woman of dyspeptic habits, became pregnant, and had arrived at the full period of utero-gestar tion. During the early period of pregnancy she suffexed considerably from stomach symptoms, and during the last fortnight laboured under severe cold, with cough and copions expectoration, to which she paid no attention. I should mention, as a fact bearing in eome measure perhaps upos the case, that twelve days before her confinement her nerrous system had received a severe shock from an urguarded expression of a neighbour, which caused her extreme anxiety, and no little fear for the life of her husband.

On the 7th of March last, at three o'clock in the morning, she was roused from her sleep by the escape of the liquor amnii, which was the first intimation of the com mencement of labour. Parturition graduelly adranech; 